\title{
Os institutos de pesquisa no desenvolvimento científico ө tecnológico na Amazônia
}

Um considerável esforço foi desenvolvido nos últimos anos com o objetivo de avaliar o processo de desenvolvimento científico e tecnológico, no Brasil. Grande ênfase foi atribuída, nesse trabalho, à função do Governo, na formulação e implementação da política científica nacional. Entretanto, pouco se tem pensado sobre o papel do Estado como executor de programas de investigação, tarefa considerada residual, entre as muitas desenvolvidas pelo CNPq.

A década de 80 inicia-se dentro de uma nova conjuntura nacional e internacional, caracterizada pela escassez de recursos. É cada vez mais necessário associar em uma mesma direção os esforços dos di versos componentes do Sistema Nacional de Desenvolvimento Científico e Tecnológico.

O sucesso dessa política depende fundamentalmente da capacidade criadora dos administradores, pesquisadores e técnicos que deverão procurar formas mais eficazes de administração dos recursos disponíveis. Nesse sentido, é importante pensar no papel dos Institutos do CNPq, particularmente aqueles da Região Amazônica e examinar de que forma seu potencial pode ser aproveitado ao máximo, em benefício do desenvolvimento regional.

O CNPq, no âmbito do Sistema Nacional de Desenvolvimento Científico e Tecnológico, desempenha três funções básicas:

- Coordenação e planejamento da política de desenvolvimento científico e tecnológico; lógica;

- Fomento e apoio à execução da pesquisa científica e tecno-

- Execução direta, através dos Institutos de Pesquisa do CNPq, presentemente vinculados à Vice-Presidência.

Com relação a esta última, é importante, lembrar que, entre os instrumentos mais eficazes no estabelecimento de uma ponte entre os interesses do Governo e os da Comunidade científica dos países mais desenvolvidos, encontram-se os chamados institutos ou centros nacionais de pesquisa.

Esses institutos podem ser de dois tipos:

1 - centros de excelência, complementares ao sistema acadêmico/universitário ou

2 - centros voltados para problemas ligados a problemas de grande relevância nacional.

Os pré-requisitos para que centros do primeiro tipo assumam um papel decisivo no Sistema Nacional de Desenvolvimento Científico e Tecnológico são: qualidade excepcional da produção científica e pres- 
tígio nacional, permitindo que sejam reconhecidos como líderes de programas/projetos em seus campos respectivos de conhecimento, facilitando o intercâmbio a nivel nacional e estabelecendo prestígio internacional.

Para o segundo tipo de instituição, adota-se como modelo: a especialização no trato de problemas relevantes para a política nacional de desenvolvimento e a capacitação em áreas científicas e tecnológicas, destacando-a no contexto nacional e internacional.

Assim, esses centros nacionais ou institutos de pesquisa devem ser caracterizados:

1 - pela ênfase no desenvolvimento de capacidade científica e tecnológica voltada para a solução de problemas nacionais;

2 - pelo potencial que apresentam no sentido de contribuir para o fomento da demanda de tecnologia produzida no País e

3 - pelas possibilidades de superação dos limites e condicionamentos da formação acadêmica tradicional.

No que se refere à formação de recursos humanos, nos centros do primeiro tipo, desenvolvem-se pós-doutoramento e especialização em atividades de investigação altamente qualificados. Nos centros do segundo tipo, formação e desenvolvimento de especialistas não disponiveis no mercado.

Outros benefícios existentes em ambos os tipos de organização são: possibilidade de promover processos não convencionais de treinamento e formação de recursos humanos (ex: ano sabático); disponibilidade de instalações ou ramificações, distribuidas em qualquer ponto do território nacional; facilidade na aquisição de equipamentos de alto custo, permanentemente à disposição de suas equipes bem como de outros segmentos da comunidade acadêmica; capacidade de prover aos projetos condições de estabilidade e continuidade dificilmente disponíveis, no âmbito das universidades.

Considerando os requisitos anteriormente assinalados, o $\mathrm{CNPq}$ tem procurado criar as condições para que seus Institutos passem a se constituir em instituições científicas padrão, tarefa que vem mobilizando a Vice-Presidência, à qual os Institutos estão vinculados.

Espera-se que, neste processo, os Institutos localizados na Região Amazônica venham a cumprir um papel decisivo na transformação do quadro de dificuldades e carências em que se encontra o processo de desenvolvimento científico e tecnológico regional. Esta ação, no entanto, deverá se dar de forma complementar àquela exercida pela Universidade e em íntima colaboração com a Comunidade científica local.

Finalmente, cumpre lembrar que as dificuldades ocasionadas pelo contexto regional podem ser reconhecidas, mas que não se pode abrir mão do padrão de excelência que justifique o patrocínio do $\mathrm{CNPq}$ às atividades desenvolvidas no INPA e no MPEG. Essa tarefa requer a clara consciência de todos os que se interessam pelo desenvolvimento da Amazônia.

\section{Guilherme Mauricio Souza Marcos De La Penha Vice-Presidente do CNPq}

